\title{
Alpha lipoic acid selectively inhibits proliferation and adhesion to fibronectin of v-H-ras-transformed 3Y1 cells
}

\author{
Masao Yamasaki, Masahiro Iwase, Kazuo Kawano, Yoichi Sakakibara, Masahito Suiko and Kazuo Nishiyama* \\ Department of Biochemistry and Applied Biosciences, Faculty of Agriculture, University of Miyazaki, 1-1 Gakuenkibanadai-nishi, Miyazaki 889-2192, Japan
}

(Received 1 May, 2011; Accepted 8 August, 2011)

\begin{abstract}
Here, we focused on the effects of racemic $\alpha$-lipoic acid on proliferation and adhesion properties of $3 Y 1$ rat fibroblasts and the v-H-ras-transformed derivative, HR-3Y1-2 cells. Racemic $\alpha$-lipoic acid inhibited proliferation of HR-3Y1-2 but not $3 Y 1$ cells at 0.3 and $1.0 \mathrm{mM}$. R-(+)- $\alpha$-lipoic acid also inhibited proliferation of HR3Y1-2 cells equivalent to that of racemic $\alpha$-lipoic acid. In addition, racemic $\alpha$-lipoic acid decreased intracellular reactive oxygen species levels in HR-3Y1 cells but not 3Y1 cells. Next, we evaluated the effects of racemic $\alpha$-lipoic acid on cell adhesion to fibronectin. The results indicated that racemic $\alpha$-lipoic acid decreased adhesive ability of HR-3Y1-2 cells to fibronectin-coated plates. As blocking antibody experiment revealed that $\beta 1$-integrin plays a key role in cell adhesion in this experimental system, the effects of racemic $\alpha$-lipoic acid on the expression of $\beta 1$-integrin were examined. The results indicated that racemic $\alpha$-lipoic acid selectively downregulated the expression of cell surface $\beta 1$-integrin expression in HR-3Y1-2 cells. Intriguingly, exogenous hydrogen peroxide upregulated cell surface $\beta 1$-integrin expression in $3 Y 1$ cells. Taken together, these data suggest that reduction of intracellular reactive oxygen species levels by $\alpha$-lipoic acid could be an effective means of ameliorating abnormal growth and adhesive properties in v-H-ras transformed cells.
\end{abstract}

Key Words: reactive oxygen species, $\beta 1$-integrin, abnormal growth, $3 Y 1$ cells

$\mathrm{R}$ as proteins are oncogene products capable of inducing cell transformation and are associated with many types of human cancer. Indeed, ras mutation is recognized in a broad range of human cancers. ${ }^{(1)}$ Wild-type Ras proteins play a central role in the regulation of normal cell proliferation, whereas activation mutation of Ras confers properties of cancer cells, such as deregulated proliferation. ${ }^{(2,3)}$ Recent data attribute this abnormal proliferation of cells with activation mutation of ras to overactivation of NADPH oxidase (Nox1) and resulting reactive oxygen species (ROS) production. ${ }^{(4)}$ The H-ras oncogene induces constitutive expression of Nox 1 through the Raf-MEK-MAPK pathway and Nox1-generated ROS have an essential mediating role in ras oncogene transformation phenotypes, including augmented cell growth, altered cell morphology, anchorageindependent growth, and tumorigenesis. ${ }^{(8)}$ The HR-3Y1-2 cell line established by Kimura et al..$^{(9)}$ is derived from 3 Y 1 rat fibroblasts transformed with the v-H-ras oncogene. Anchorage-independent proliferation and changes in cellular morphology are known features of $3 \mathrm{Y} 1$ cells transformed with $\mathrm{v}-\mathrm{H}-\mathrm{ras},{ }^{(10)}$ and our previous study showed that HR-3Y1-2 cells are capable of proliferating faster than the parental cell line $3 Y 1{ }^{(11)}$ Therefore, these cell lines are useful for evaluation of the effects of various treatments on the malignant characteristics associated with Ras activation. In addition, ROS production could control the integrinrelated cancer migration, which means that the adhesive ability to extracellular matrix is maintained in the normal state under the control of cellular redox conditions. ${ }^{(12)}$ Interfering with tumor cell attachment with integrin-binding peptides has been shown to be an effective strategy for antimetastatic therapy. ${ }^{(13)}$

Alpha-lipoic acid (6,8-dithio octanoic acid; ALA) is a naturally occurring antioxidative compound and is essential in humans, functioning as a coenzyme in various biological processes. ALA is widely distributed as lipoyllysine in vegetables and animal tissues. ${ }^{(14)}$ Due to its potent antioxidant activity in vitro and in vivo, it is utilized as a preventive agent in diabetes mellitus, hypertension, and hepatic disorders. ${ }^{(15-17)}$ Therefore, ALA is a promising agent for amelioration of activated ras-derived malignant characteristics by elimination of ROS. To evaluate this hypothesis, we evaluated the effects of ALA on proliferation and cell adhesion of 3Y1 and HR-3Y1-2 cells.

\section{Materials and Methods}

Chemicals. Racemic or $R-(+)-\alpha$-Lipoic acid (rac-ALA or $R$ $(+)$-ALA) and 2',7'-dichlorofluorescein diacetate (DCFH-DA) were purchased from Sigma (St. Louis, MO).

Cell culture. 3Y1 (also called 3Y1-B clone 1-6) and HR3Y1-2 cells were purchased from the Japanese Collection of Research Bioresources (Osaka, Japan). Cells were maintained in Dulbecco's modified Eagle's medium (DMEM) supplemented with $10 \%$ fetal bovine serum containing 100 units $/ \mathrm{mL}$ of penicillin $\mathrm{G}$ and $100 \mu \mathrm{g} / \mathrm{mL}$ of streptomycin. Cells were subcultured twice a week, and in actual in vitro experiments, the cells were seeded at $3.5 \times 10^{3}$ cells $/ \mathrm{cm}^{2}$ in $90-\mathrm{mm}$ dishes or 24 -well multiwell culture plates.

Cell cycle analysis. For cell cycle analysis, cells were treated with or without $1.0 \mathrm{mM}$ rac-ALA for $24 \mathrm{~h}$ and the percentage of each cell cycle population was evaluated by flow cytometric analysis. Briefly, cells were fixed in $70 \%$ methanol for $1 \mathrm{~h}$ and $50 \%$ ethanol at $4{ }^{\circ} \mathrm{C}$ overnight. Then, the nuclei were treated with $10 \mu \mathrm{g} / \mathrm{ml}$ propidium iodide and $10 \mu \mathrm{g} / \mathrm{ml}$ RNase. After staining, cell cycle analysis was performed using a COULTER Epics XL flow cytometer (Beckman Coulter, Inc., Fullerton, CA) with MultiCycle software (San Diego, CA).

Intracellular redox state. At the end of the culture period, cells were washed with ice-cold PBS and stained with $50 \mu \mathrm{M}$ DCFH-DA for $30 \mathrm{~min}$ at $37^{\circ} \mathrm{C}$. After staining, cells were subjected to flow cytometric analysis (EPICS XL; Beckman Coulter).

Cell adhesion to fibronectin. Cells at growth phase were

*To whom correspondence should be addressed.

E-mail: nishiyam@cc.miyazaki-u.ac.jp 
treated with serum-free DMEM for 60 min at $37^{\circ} \mathrm{C}$. The cells pretreated with or without rac-ALA were then recovered and seeded at $2.0 \times 10^{5}$ cells/well in fibronectin (Fn)-coated 24-well plates (BD Biosciences, San Jose, CA). After 60 min, floating cells were removed from the well and adherent cells were counted. In an antibody blocking experiment, cells were coincubated with $50 \mu \mathrm{g} / \mathrm{mL}$ of purified hamster anti-rat CD29 (Invitrogen, Carlsbad, CA) or hamster IgM (Beckman Coulter) as an isotype control.

Western blotting analysis. Whole cell $\beta 1$-integrin and $\beta$ actin were detected by Western blotting analysis. At the end of the culture period, cells were lysed in $50 \mathrm{mM}$ Tris- $\mathrm{HCl}$ (pH 7.5) containing $150 \mathrm{mM} \mathrm{NaCl}, 2 \%$ Triton X-100, $2 \mathrm{mM}$ EDTA, $50 \mathrm{mM} \mathrm{NaF}, 30 \mathrm{mM} \mathrm{Na} 4 \mathrm{P}_{2} \mathrm{O}_{7}$, and 1/50 vol. protease inhibitor cocktail (Nacalai Tesque, Kyoto, Japan). Protein concentrations were measured using the BCA protein assay reagent (Pierce, Rockford, IL). Lysates containing $10 \mu \mathrm{g}$ of protein were separated by electrophoresis on $10 \%$ SDS-polyacrylamide gels, and transferred onto PVDF Hybond-P membranes (Amersham-Pharmacia Biotech, Buckinghamshire, UK). Blocking was performed using $3 \%$ defatted milk in Tris-buffered saline with $0.1 \%$ Tween-20 (TTBS), and antibodies were diluted in Can Get Signal solutions 1 and 2 (Toyobo, Tokyo, Japan). Anti- $\beta 1$-integrin (N-20) and horseradish peroxidase-conjugated donkey anti-goat IgG were purchased from Santa Cruz Biotechnology (Santa Cruz, CA). The membranes were washed with TTBS after each antibody binding reaction. Detection of each protein was performed using an ECL Plus kit (Amersham-Pharmacia).

Cell surface $\beta 1$-integrin expression. At the end of the culture period, cells were washed with cold PBS, then incubated with $2 \mu \mathrm{g} / \mathrm{mL}$ of hamster anti-mouse CD29 FITC-conjugate (clone HM beta 1-1, AbD Serotec, Kidlington, UK) for 30 min at $4{ }^{\circ} \mathrm{C}$. Cells were washed and resuspend into $2 \% \mathrm{FBS}, 2 \mathrm{mM}$


Fig. 1. Effects of ALA on proliferation of $3 Y 1$ or HR-3Y1-2 cells. Cultures were treated with $0,0.1,0.3,1.0 \mathrm{mM}$ rac-ALA (A) or $R$ - $(+)$-ALA (B) for $24 \mathrm{~h}$. Results are means \pm SD of 3 samples. Values marked with a dagger mark or asterisk are significantly different from the data in $3 Y 1$ control or control value in each cell line at Values marked with a dagger mark or asterisk are significantly different from the data in $3 Y 1$ control or control value in each cell line at $p<0.05$, respectively. Open column shows $3 Y 1$ cells and shaded column shows HR-3Y1-2 cells and "None" means that cells were not treated with ALA.
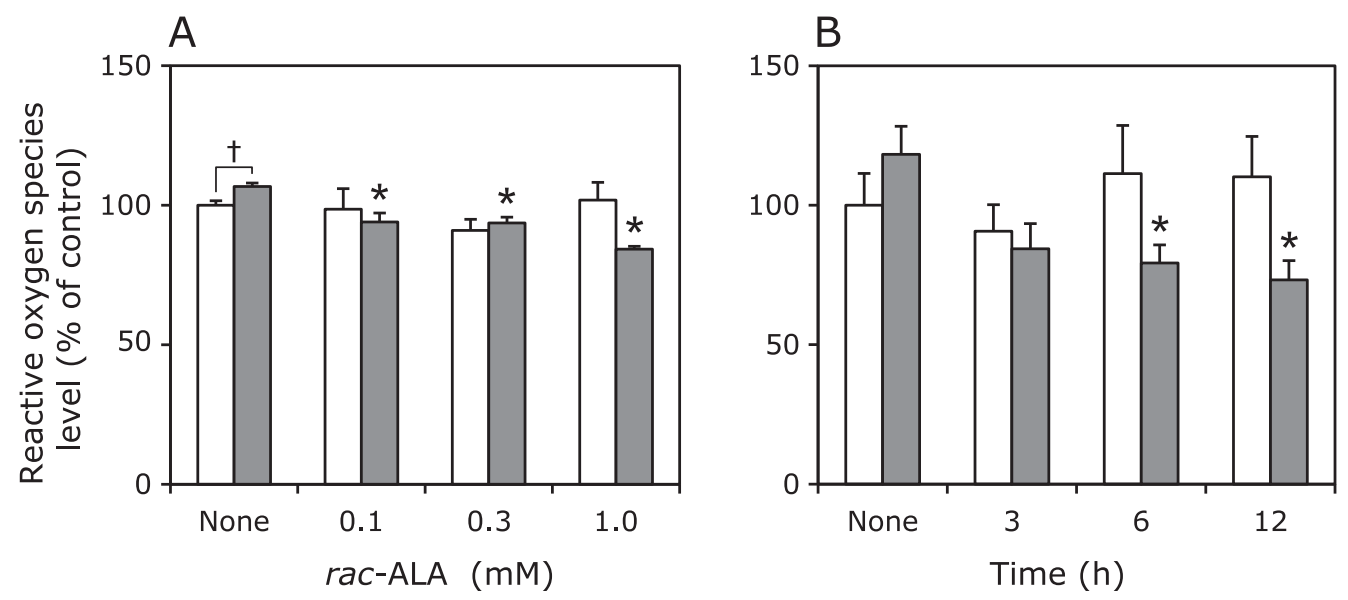

Fig. 2. Intracellular ROS levels in $3 Y 1$ and HR-3Y1-2 cells. Cells were treated with $0,0.1,0.3,1.0 \mathrm{mM}$ rac-ALA for $12 \mathrm{~h}$ (A), $0,1.0 \mathrm{mM}$ rac-ALA for 0 $3,6,12 \mathrm{~h}$ (B). The production of ROS was measured using the oxidation-sensitive fluorescent probe $2^{\prime} 7^{\prime}$-dichlorodihydrofluorescin diacetate. Results are means \pm SD of 3 independent experiments. Values marked with a dagger mark or asterisk are significantly different from the data in $3 Y 1$ control or control value in each cell line at $p<0.05$, respectively. Open column shows $3 Y 1$ cells and shaded column shows HR-3Y1-2 cells and "None" means that cells were not treated with rac-ALA. 
Table 1. Effect of racemic alpha-lipoic acid on the cell cycle progression of 3 Y 1 cells and HR-3Y1-2 cells

\begin{tabular}{lccccc}
\hline & & \multicolumn{3}{c}{ rac-ALA (mM) } \\
\cline { 2 - 6 } & & None & 0.1 & 0.3 & 1 \\
\hline \multirow{2}{*}{ 3Y1 Distribution (\%) } & G1 & $50.6 \pm 0.6$ & $51.3 \pm 2.6$ & $54.3 \pm 2.2$ & $54.6 \pm 2.1$ \\
& S & $39.7 \pm 1.7$ & $38.9 \pm 4.0$ & $34.8 \pm 4.7$ & $35.7 \pm 0.5$ \\
\hline \multirow{3}{*}{ HR-3Y1-2 Distribution (\%) } & G1/M & $9.5 \pm 2.3$ & $9.6 \pm 2.1$ & $10.7 \pm 2.6$ & $9.5 \pm 2.0$ \\
& G & $33.9 \pm 0.2$ & $35.3 \pm 0.4$ & $38.9 \pm 0.8^{*}$ & $45.0 \pm 0.7^{*}$ \\
& G2/M & $54.0 \pm 2.7$ & $54.5 \pm 0.4$ & $49.9 \pm 3.0$ & $45.4 \pm 3.4^{*}$ \\
\hline
\end{tabular}

Data are means \pm SD for 3 samples. Values with asterisk mark(s) are significantly different from the None in each cell cycle phase.
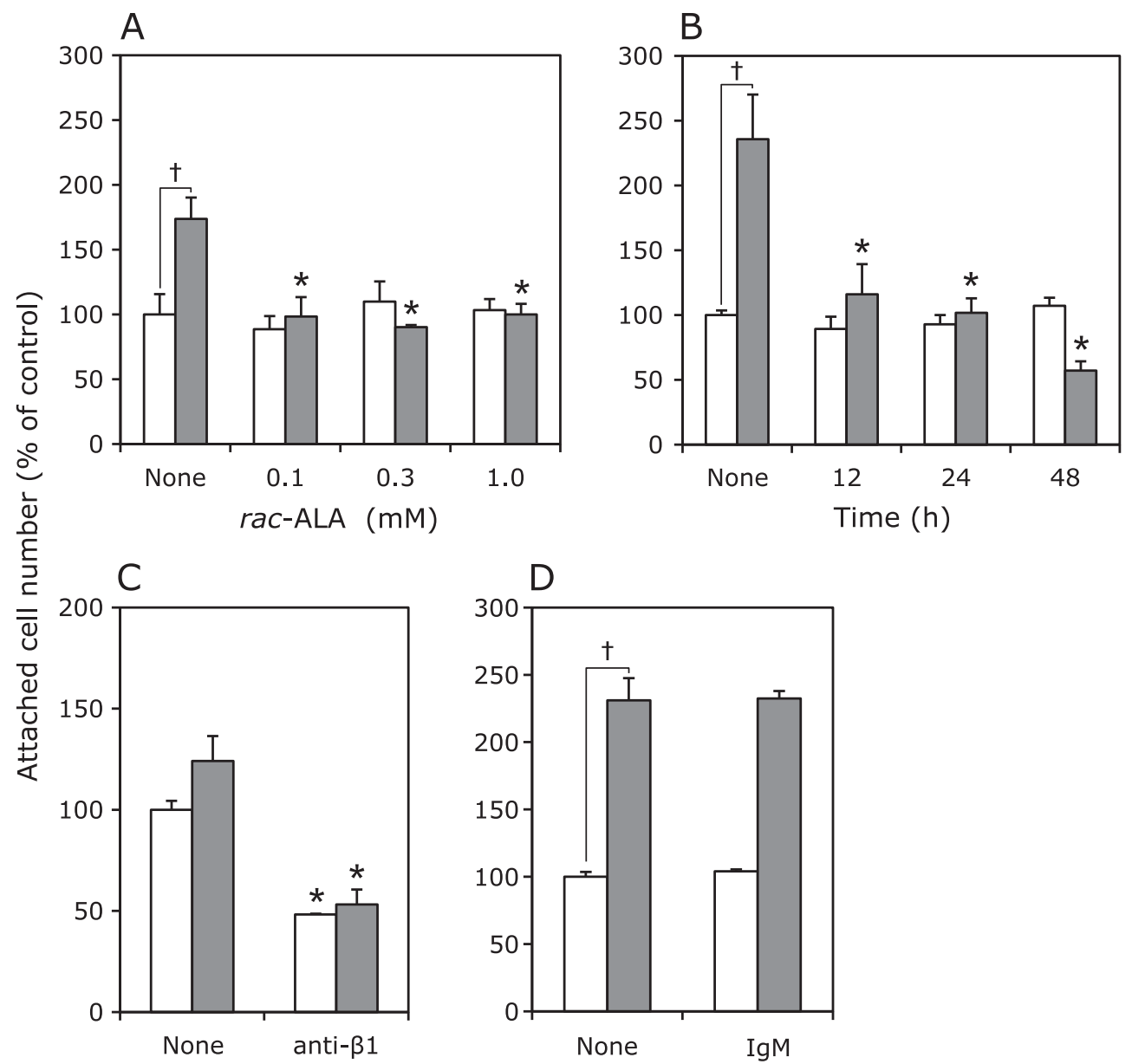

Fig. 3. Adhesion of $3 Y 1$ and HR-3Y1-2 cells to fibronectin. Cells were treated with $0,0.1,0.3,1.0 \mathrm{mM}$ rac-ALA for $48 \mathrm{~h}$ (A) or $0,1.0 \mathrm{mM}$ rac-ALA for $0,12,24,48 \mathrm{~h}(\mathrm{~B})$ and then incubated in fibronectin-coated plates at $37^{\circ} \mathrm{C}$ for $60 \mathrm{~min}$. In the antibody blocking experiment, cells were incubated with anti- $\beta 1$-integrin antibody $(50 \mu \mathrm{g} / \mathrm{mL})(C)$ or hamster $\operatorname{lgM}(50 \mu \mathrm{g} / \mathrm{mL})$ as an isotype control (D). Floating cells were removed and adherent cells were counted. Results are means \pm SD of 3 samples. Values marked with a dagger mark or asterisk are significantly different from the data in $3 Y 1$ control or control value in each cell line at $p<0.05$, respectively. Open column shows $3 Y 1$ cells and shaded column shows HR-3Y1-2 cells and "None" means that cells were not treated with rac-ALA.

EDTA/PBS and subjected flow cytometric analysis (EPICS XL). Cells were stained with $10 \mu \mathrm{g} / \mathrm{ml}$ propidium iodide to eliminate dead cell from analysis.

Statistical analysis. Statistical analysis was done with 4 Steps Statcel2 software (OMS Publishing, Saitama, Japan). Data were analyzed by the Tukey-Kramer test, and differences at $p<0.05$ were considered significant.

\section{Results}

Growth inhibition and cell cycle anaysis. First, we evaluated the effects of rac-ALA on the growth of $3 \mathrm{Y} 1$ and HR-3Y12 cells. The results indicated that 0.3 and $1.0 \mathrm{mM}$ rac-ALA significantly prevented the growth of HR-3Y1-2 but not 3 Y 1 cells at 24 h. (Fig. 1A). To know whether two enantiometric forms of ALA has different effect on the proliferation of HR-3Y1-2 cells, 

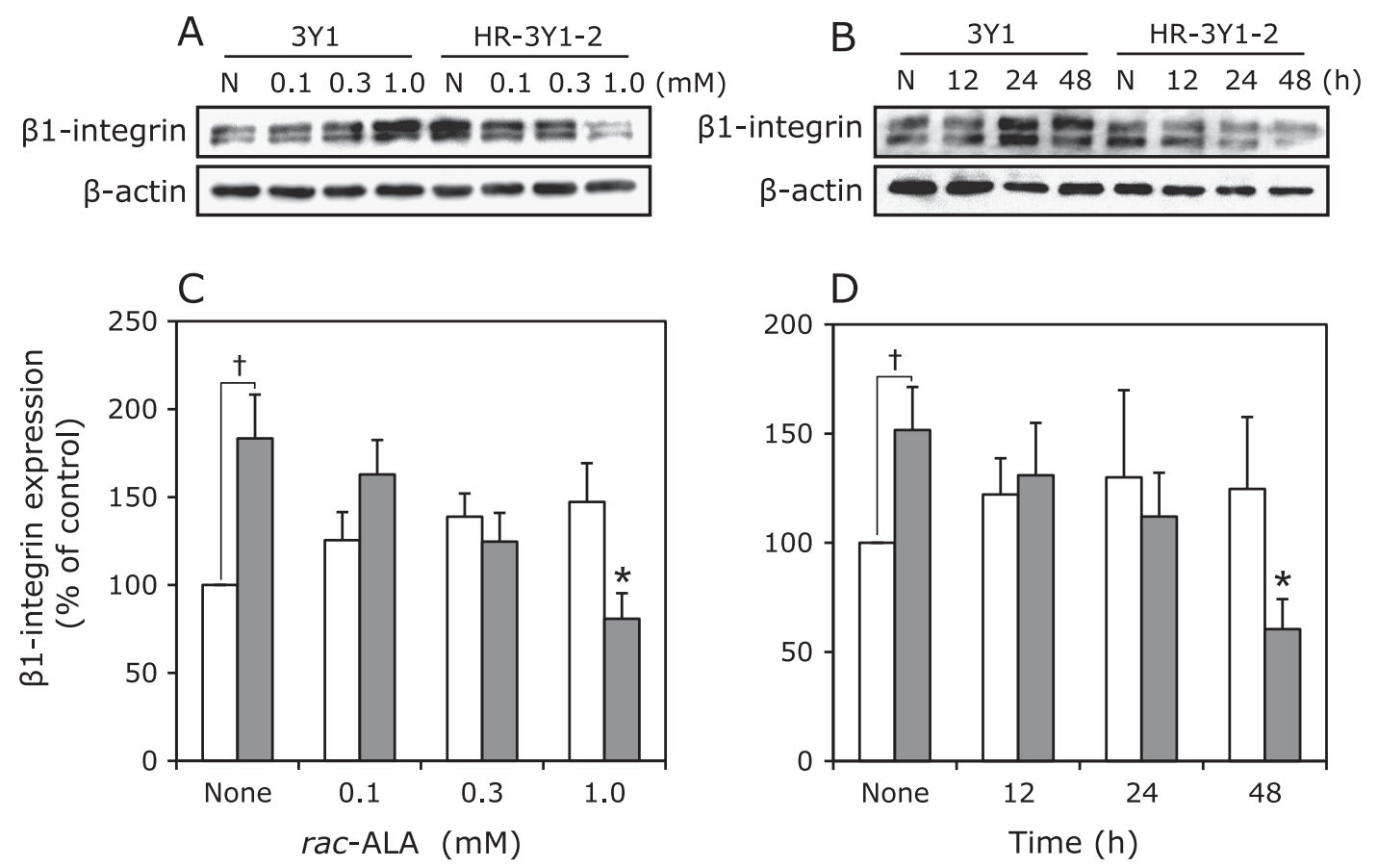

Fig. 4. $\quad \beta 1$-Integrin protein expression in $3 Y 1$ and HR-3Y1-2 cells. Cells were treated with $0,0.1,0.3,1.0 \mathrm{mM}$ rac-ALA for $48 \mathrm{~h}(\mathrm{~A}, \mathrm{C})$ or $0,1.0 \mathrm{mM}$ racALA for $0,12,24,48 \mathrm{~h}(\mathrm{~B}, \mathrm{D})$. $\beta 1$-Integrin protein was detected by western blotting and representative image data were shown in $A$ and $B$, density of each band was quantified as a ratio of $\beta 1$-integrin/ $\beta$-actin and shown in $C$ and $D$. The methods are described in detail in Materials and Methods. Results in C and D are means \pm SD of 3 independent experiments. Values marked with a dagger mark or asterisk are significantly different from the data in $3 Y 1$ control or control value in each cell line at $p<0.05$, respectively. Open column shows $3 Y 1$ cells and shaded column shows HR-3Y1-2 cells and "None" and "N" mean that cells were not treated with rac-ALA.

cells were treated with $0,0.1,0.3$ and $1.0 \mathrm{mM} R$-(+)-ALA. As a result, $R-(+)-$ ALA also inhibited proliferation of HR-3Y1-2 equivalent to that of $\mathrm{rac}$-ALA. To determine if $\mathrm{rac}$-ALA regulated cell cycle progression, cells were treated with 0 to $1.0 \mathrm{mM} \mathrm{rac}$ ALA and subjected to cell cycle analysis. Results showed that the G1 phase cell population was increased with decrease of S phase distribution at 0.3 and $1.0 \mathrm{mM} \mathrm{rac}$-ALA treatment in HR-3Y1-2 cells (Table 1), whereas rac-ALA did not affect the cell cycle progression on the $3 \mathrm{Y} 1$ cells.

Intracellular ROS level. To evaluate the relationship between ROS accumulation and HR-3Y1-2-selective inhibition of proliferation, cells were stained with DCFH-DA to determine intracellular ROS levels in 3Y1 and HR-3Y1-2 cells. Intracellular ROS levels were slightly higher in HR-3Y1-2 cells than in 3 Y 1 cells. The results indicated that rac-ALA at $0.1,0.3$ and $1.0 \mathrm{mM}$ treatment for $12 \mathrm{~h}$ caused a substantial decrease in intracellular ROS level at $12 \mathrm{~h}$ HR-3Y1-2 cells (Fig. 2 A and B). In contrast, rac-ALA induced no changes in $3 \mathrm{Y} 1$ cells.

Cell adhesion to fibronectin. As rac-ALA selectively inhibited the proliferation of HR-3Y1-2 cells and cellular ROS level, we next evaluated the effects of $r a c$-ALA on integrin-related cell adhesion. As shown in Fig. 3, HR-3Y1-2 cells had greater adhesive ability to fibronectin-coated plates. HR-3Y1-2 cells pretreated with $0.1,0.3$ and $1.0 \mathrm{mM}$ rac-ALA for $48 \mathrm{~h}$ (Fig. 3A) or $1.0 \mathrm{mM}$ for 12,24 and $48 \mathrm{~h}$ (Fig. 3B) showed reduced adhesion to fibronectin-coated plates. On the other hand, rac-ALA did not affect the adhesive ability of 3 Y 1 cells (Fig. 3 A and B). $\beta 1$ Integrin blocking antibody inhibited the adhesion of $3 \mathrm{Y} 1$ and HR-3Y $1-2$ cells by $51 \%$ and $57 \%$, respectively (Fig. 3C). Hamster IgM used as an isotype control did not affect adhesive ability of both cell lines (Fig. 3D). This result indicated that adhesion of these cell lines to fibronectin is due to $\beta 1$-integrin and fibronectin interaction.
Whole cell $\beta 1$-integrin expression. As shown in Fig. 3, $\beta 1$-integrin plays a pivotal role in adhesion to fibronectin in these cell lines. We next examined whether rac-ALA could downregulate $\beta 1$-integrin expression in HR-3Y1-2 cells. Fig. 4 A and B show representative blotting pictures of $\beta 1$-integrin expression and intensity of bands on a blot was quantified and shown in Fig. 4 $\mathrm{C}$ and D. Basically, untreated HR-3Y1-2 cells expressed higher levels of $\beta 1$-integrin than $3 \mathrm{Y} 1$ cells. rac-ALA at $1.0 \mathrm{mM}$ but not at 0.1 and $0.3 \mathrm{mM}$ significantly downregulated the expression of $\beta 1$-integrin at $48 \mathrm{~h}$ in HR-3Y1-2 cells, whereas its expression was unaffected by rac-ALA treatment in $3 \mathrm{Y} 1$ cells.

Cell surface $\beta 1$-integrin expression. Next, cell surface $\beta 1$ integrin expression was also examined. HR-3Y1-2 cells treated with $0.1,0.3$ and $1.0 \mathrm{mM} \mathrm{rac}$-ALA for $48 \mathrm{~h}$ (Fig. $5 \mathrm{~A}$ ) or $1.0 \mathrm{mM}$ for 12, 24 and $48 \mathrm{~h}$ (Fig. 5B) showed reduced expression of cell surface $\beta 1$-integrin. To reveal whether exogenous oxidative stress evokes HR-3Y1-2 like phenotype in 3Y1 cells, cell surface $\beta 1$ integrin expression in $3 \mathrm{Y} 1$ cells treated with hydrogen peroxide. Result showed exogenous hydrogen peroxide dose-dependently unregulated cell surface $\beta 1$-integrin expression in $3 \mathrm{Y} 1$ cells and cells treated with $100 \mu \mathrm{M}$ hydrogen peroxide for $48 \mathrm{~h}$ expressed comparable level of cell surface $\beta 1$-integrin with HR-3Y1-2 cells (Fig. 5C).

\section{Discussion}

Ras is known to play a pivotal role in regulating cell proliferation by activation of mitogen-activated protein kinase and phosphoinositide 3-kinase pathways, ${ }^{(2,3)}$ and mutations leading to activation of these cascades result in abnormal growth. There is accumulating evidence that activation mutation of $\mathrm{H}$-ras triggers the activation of Nox 1 and the resultant ROS production plays important roles in the malignant characteristics of ras-transformed 


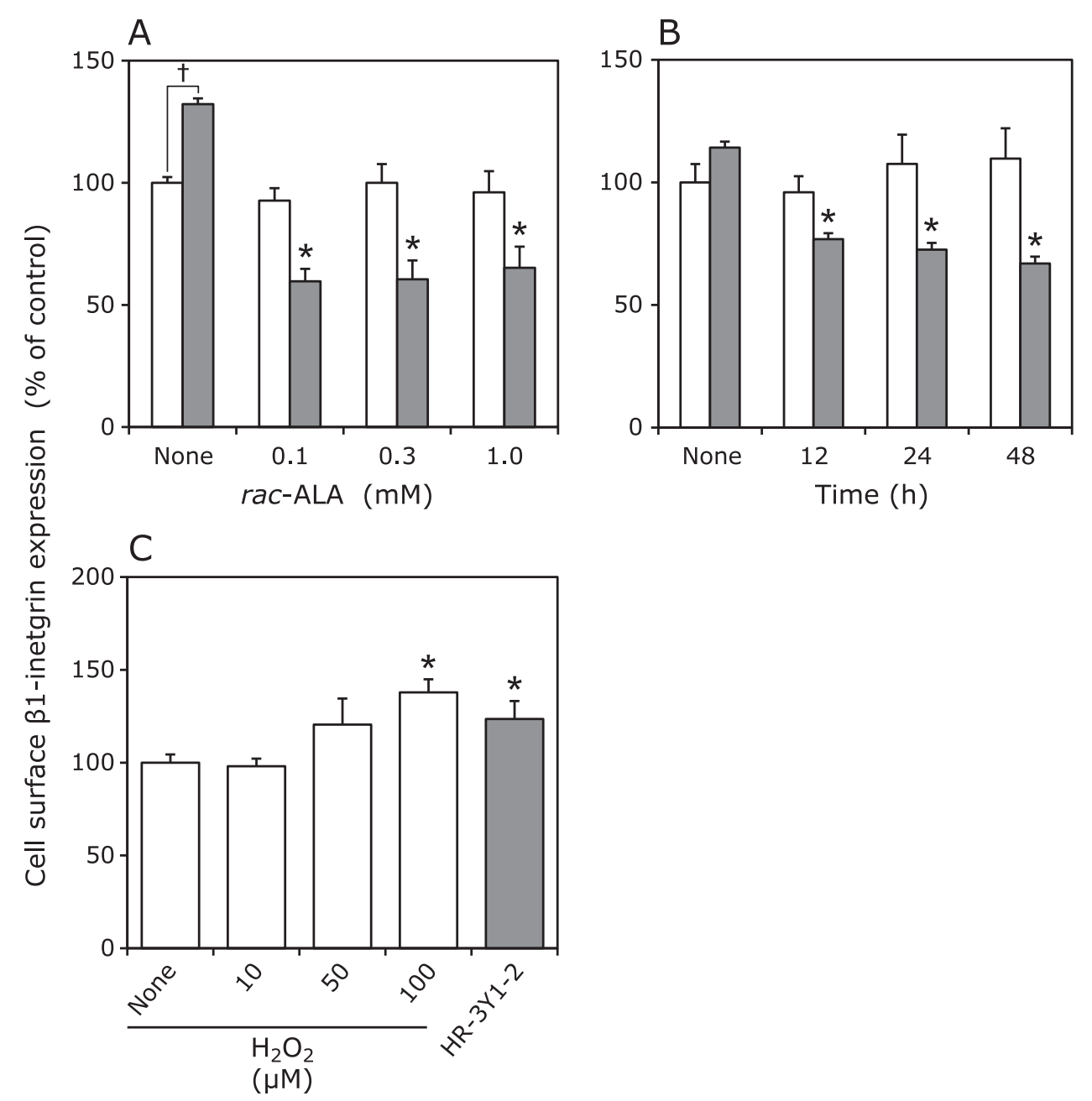

Fig. 5. Cell surface $\beta 1$-integrin protein expression in $3 Y 1$ and HR-3Y1-2 cells. Cells were treated with $0,0.1,0.3,1.0 \mathrm{mM}$ rac-ALA for $48 \mathrm{~h}$ (A), 0 , $1.0 \mathrm{mM}$ rac-ALA for $0,12,24,48 \mathrm{~h}$ (B) or $0,10,50,100 \mu \mathrm{M}$ hydrogen peroxide for $48 \mathrm{~h}$ (C). The methods are described in detail in Materials and Methods. Results in A-C are means \pm SD of 3 independent experiments. Values marked with a dagger or asterisk(s) are significantly different from the control of $3 Y 1$ cells or control of each cell line at $p<0.05$, respectively. Open column shows $3 Y 1$ cells and shaded column shows HR-3Y1-2 cells and "None" means that cells were not treated with rac-ALA.

cells. ${ }^{(4-7)}$ These results provide new insight into the mechanism by which antioxidants could decrease excess intracellular ROS then inhibit abnormal proliferation. Our data clearly showed that HR-3Y1-2 cells have higher levels of intracellular ROS than 3Y1 cells. In addition, the growth rate, ability to adhere to fibronectin, and $\beta 1$-integrin expression of HR-3Y1-2 cells were higher than those of $3 \mathrm{Y} 1$ cells. ROS behaves as a second messenger to activate the ERK pathway, which is a representative mitogenic signaling pathway. ${ }^{(18)}$ Therefore, the observation that HR-3Y1-2 cells could proliferate faster than $3 \mathrm{Y} 1$ cells is convincing. Therefore, $3 \mathrm{Y} 1$ and HR-3Y1-2 cells are considered appropriate cell lines for evaluation of the effects of antioxidants on v-H-ras mediated transformation.

Several studies have shown that ALA elicits apoptotic cell death or growth arrest in several cancer cell lines. ${ }^{(19-22)}$ However, the detailed mechanism remains to be elucidated. On the other hand, ALA is capable of preventing apoptotic cell death under conditions of oxidative stress because of its antioxidant activity. ${ }^{(23,24)}$ The results of the present study indicated that rac-ALA downregulates intracellular ROS level accompanied by inhibition of cell proliferation in HR-3Y1-2 cells, whereas rac-ALA does not affect ROS level or cell proliferation of $3 \mathrm{Y} 1$ cells at $1.0 \mathrm{mM}$. In addition, our present data revealed that $R-(+)$-ALA and rac-ALA had comparable ability of inhibiting proliferation of HR-3Y1-2 cells, suggesting naturally occurring ALA is capable of inhibiting the proliferation of v-H-ras transformed cells. Since, Smith et al. ${ }^{(25)}$ reported that protective effect against oxidative damage of ALA is different among the type of optical isomer and cell type, our subject for further study is to demonstrate the effect of ALA on various $\mathrm{v}-\mathrm{H}-$ ras transformed cells and apply to human cancer cells with H-ras mutation.

As shown in Table 1, growth-inhibitory action of rac-ALA on HR-3Y1-2 cells is attributable to cell cycle delay at G1 phase. Such reduction of intracellular ROS may be explained on the basis of several previous reports. First, ALA and its reduced form, dihydrolipoic acid (DHLA), are capable of scavenging a variety of ROS and reactive nitrogen species. ${ }^{(26)}$ Moreover, as the reduction of ALA to DHLA requires NADPH consumption, ${ }^{(27)} \mathrm{NADPH}$ starvation may indirectly prevent NADPH oxidase-derived ROS production. Secondly, LA appears to be a potent inducer of Nrf 2-mediated antioxidant gene expression, which leads to increase or maintenance of intracellular GSH. ${ }^{(28,29)}$ Actually, Moini et $a l{ }^{(30)}$ revealed that $R-(+)-L A$ significantly increased cellular reduced glutathione level and at the same time points the 
intracellular level of oxidants was decreased.

Excess intracellular ROS controls cancer metastasis and invasion by disruption of normal expression of adhesive molecules. For example, upregulation of intracellular ROS by Helicobacter pylori infection leads to an increase in $\beta 1$-integrin expression. ${ }^{(31)}$ Our data also indicated that whole cell and cell surface $\beta 1$-integrin expression is upregulated in HR-3Y1-2 cells to a greater extent than 3 Y 1 cells. $\beta 1$-Integrin can form heterodimers with $\alpha \mathrm{v}, \alpha 5$ and $\alpha 8$ chain, and these complexes have been implicated in interaction with fibronectin. Therefore, upregulation of $\beta 1$-integrin expression in HR-3Y1-2 cells is considered to result in high adhesive ability to fibronectin. Especially, some tumor cells express high levels of $\alpha 4 \beta 1$ and $\alpha 5 \beta 1$ integrin in association with malignant phenotypes, such as metastasis and anchorageindependent proliferation. Consistent with these reports, our data indicated that HR-3Y1-2 cells had higher ability to adhere to fibronectin than $3 \mathrm{Y} 1$ cells. Moreover, as the blocking experiment indicated that adhesion of $3 \mathrm{Y} 1$ and HR-3Y1-2 cells was substantially prevented by anti- $\beta 1$-integrin antibody, $\beta 1$-integrin plays a pivotal role in adhesion with fibronectin in both cell lines. Intriguingly, rac-ALA treatment prevented adhesion of HR-3Y12 cells to fibronectin at $0.1,0.3$ and $1.0 \mathrm{mM}$ (Fig. 3) with downregulation of cell surface $\beta 1$-expression (Fig. 5). On the other hand, although $1.0 \mathrm{mM} \mathrm{rac}$-ALA surely downregulated whole cell $\beta 1$-integrin expression in HR-3Y1-2, low concentrations of racALA $(0.1,0.3 \mathrm{mM})$ could not. These data suggest that rac-ALA reduced adhesive ability of HR-3Y1-2 cells to fibronectin through downregulation of cell surface $\beta 1$-integrin expression by regulating its cellular localization. It is increasingly evident that cell surface $\beta 1$-integrin level is regulated by its dynamic internalization and recycling process. ${ }^{(32,33)}$ As downregulation of cell surface $\beta 1$-integrin by rac-ALA was apparent after $12 \mathrm{~h}$ of treatment as shown in Fig. 5, which was after ROS inhibition, downregulation of cell surface $\beta 1$-integrin expression in HR-3Y1-2 cells is dependent on ROS-related pathways. Moreover, exogenous hydrogen peroxide is capable of upregulating cell surface $\beta 1$ -

\section{References}

1 Bamford S, Dawson E, Forbes S, et al. The COSMIC (Catalogue of Somatic Mutations in Cancer) database and website. Br J Cancer 2004; 91: 355-358.

2 Karnoub AE, Weinberg RA. Ras oncogenes: split personalities. Nat Rev Mol Cell Biol 2008; 9: 517-531.

3 Schubbert S, Shannon K, Bollag G. Hyperactive Ras in developmental disorders and cancer. Nat Rev Cancer 2007; 7: 295-308.

4 Irani K, Xia Y, Zweier JL, et al. Mitogenic signaling mediated by oxidants in Ras-transformed fibroblasts. Science 1997; 275: 1649-1652.

5 Shinohara M, Shang WH, Kubodera M, et al. Nox1 redox signaling mediates oncogenic Ras-induced disruption of stress fibers and focal adhesions by down-regulating Rho. J Biol Chem 2007; 282: 17640-17648.

6 Lynch OT, Giembycz MA, Barnes PJ, Lindsay MA. Pharmacological comparison of LTB(4)-induced NADPH oxidase activation in adherent and non-adherent guinea-pig eosinophils. Br J Pharmacol 2001; 134: 797-806.

7 Serezani CH, Aronoff DM, Jancar S, Peters-Golden M. Leukotriene B4 mediates $\mathrm{p} 47$ phox phosphorylation and membrane translocation in polyunsaturated fatty acid-stimulated neutrophils. J Leukoc Biol 2005; 78: 976984.

8 Mitsushita J, Lambeth JD, Kamata T. The superoxide-generating oxidase Nox 1 is functionally required for Ras oncogene transformation. Cancer Res 2004; 64: 3580-3585

9 Shimura H, Mitsudomi T, Matsuzaki A, Kabemura M, Okuda A, Kimura G. Transformation by $\mathrm{v}-\mathrm{H}-\mathrm{ras}$ does not restore proliferation of a set of temperature-sensitive cell-cycle mutants of rat 3Y1 fibroblasts. Cell Struct Funct 1990; 15: 211-219.

10 Zaitsu H, Tanaka H, Mitsudomi T, Matsuzaki A, Ohtsu M, Kimura G. Differences in proliferation properties among sublines of rat $3 \mathrm{Y} 1$ fibroblasts transformed by various agents in vitro. Biomed Res 1988; 9: 181-197.

11 Yamasaki M, Omi Y, Fujii N, et al. Mustard oil in "Shibori Daikon" a variety of Japanese radish, selectively inhibits the proliferation of $\mathrm{H}$-ras-transformed integrin expression in $3 \mathrm{Y} 1$ cells (Fig. 5C). On the contrary, exogenous hydrogen peroxide downregulates $\beta 1$-integrin expression in promyelocytic leukemia. ${ }^{(34)}$ These information indicate that intracellular ROS manipulates $\beta 1$-integrin expression.

We can't avoid discussing about another plausible mechanism of ALA. ALA may directly interact with cysteine residue of the proteins involved in various cellular signaling pathways. For instance, ALA downregulates phosphatases such as PP2A through the redox modulation of cysteine residues because ALA occurs thiol-disulfide exchange between ALA and protein sulfhydryls. ${ }^{(29)}$ As PP2A has positive role in H-ras dependent activation of Raf-1 which consequently activates ERK pathway, ${ }^{(35)}$ ALA promises downregulation of ERK pathway through inactivation of PP2A. On the other hand, as cysteine-rich-domain in Raf- 1 protein is also involved its activation and ERK2 also has cysteine residue in its active site, the interaction between ALA and cysteine residue(s) in these or other signaling proteins is mostly unknown. Further studies are needed to focus on the molecular mechanism of ALA including redox modulation of signaling molecules.

Taken together, ALA is a promising agent to decrease intracellular ROS and ameliorate the malignant characteristics of v-Haras-transformed cells.

\section{Acknowledgments}

This work is supported by Grant-in Aid Scientific Research (C) No. 20580137.

\section{Abbreviations}

$\begin{array}{ll}\text { ALA } & \alpha \text {-lipoic acid } \\ \text { DCF } & 2^{\prime}, 7^{\prime} \text {-dichlorofluorescin } \\ \text { DCFH-DA } & 2^{\prime}, 7^{\prime} \text {-dichlorofluorescein diacetate } \\ \text { DMEM } & \text { Dulbecco's modified Eagle's medium } \\ \text { ROS } & \text { reactive oxygen species }\end{array}$

3 Y1 cells. Biosci Biotechnol Biochem 2009; 73: 2217-2221.

12 Sadok A, Bourgarel-Rey V, Gattacceca F, Penel C, Lehmann M, Kovacic H. Nox1-dependent superoxide production controls colon adenocarcinoma cell migration. Biochim Biophys Acta 2008; 1783: 23-33.

13 Desgrosellier JS, Cheresh DA. Integrins in cancer: biological implications and therapeutic opportunities. Nat Rev Cancer 2010; 10: 9-22.

14 Lodge JK, Youn HD, Handelman GJ, et al. Natural sources of lipoic acid determination of lipoyllysine released from protease-digested tissues by high performance liquid chromatography incorporating electrochemical detection. J Appl Nutr 1997; 49: 3-11.

15 Packer L, Kraemer K, Rimbach G. Molecular aspects of lipoic acid in the prevention of diabetes complications. Nutrition 2001; 17: 888-895.

16 Vasdev S, Ford CA, Parai S, Longerich L, Gadag V. Dietary alpha-lipoic acid supplementation lowers blood pressure in spontaneously hypertensive rats. J Hypertens 2000; 18: 567-573.

17 Bustamante J, Lodge JK, Marcocci L, Tritschler HJ, Packer L, Rihn BH. Alpha-lipoic acid in liver metabolism and disease. Free Radic Biol Med 1998; 24: 1023-1039.

18 Traore K, Sharma R, Thimmulappa RK, Watson WH, Biswal S, Trush MA. Redox-regulation of Erk1/2-directed phosphatase by reactive oxygen species: role in signaling TPA-induced growth arrest in ML-1 cells. $J$ Cell Physiol 2008; 216: 276-285.

19 Marsh SA, Pat BK, Gobe GC, Coombes JS. Evidence for a non-antioxidant, dose-dependent role of alpha -lipoic acid in caspase-3 and ERK2 activation in endothelial cells. Apoptosis 2005; 10: 657-665.

20 Simbula G, Columbano A, Ledda-Columbano GM, et al. Increased ROS generation and p53 activation in alpha-lipoic acid-induced apoptosis of hepatoma cells. Apoptosis 2007; 12: 113-123.

21 Wenzel U, Nickel A, Daniel H. alpha-Lipoic acid induces apoptosis in human colon cancer cells by increasing mitochondrial respiration with a 
concomitant O2-*-generation. Apoptosis 2005; 10: 359-368.

22 Yamasaki M, Kawabe A, Nishimoto K, et al. Dihydro-alpha-lipoic acid has more potent cytotoxicity than alpha-lipoic acid. In Vitro Cell Dev Biol Anim 2009; 45: 275-280.

23 Li CJ, Zhang QM, Li MZ, Zhang JY, Yu P, Yu DM. Attenuation of myocardial apoptosis by alpha-lipoic acid through suppression of mitochondrial oxidative stress to reduce diabetic cardiomyopathy. Chin Med J 2009; 122: 2580-2586.

24 Lee BW, Kwon SJ, Chae HY, et al. Dose-related cytoprotective effect of alpha-lipoic acid on hydrogen peroxide-induced oxidative stress to pancreatic beta cells. Free Radic Res 2009; 43: 68-77.

25 Smith JR, Thiagaraj HV, Seaver B, Parker KK. Differential activity of lipoic acid enantiomers in cell culture. J Herb Pharmacother 2005; 5: 43-54.

26 Packer L, Witt EH, Tritschler HJ. Alpha-Lipoic acid as a biological antioxidant. Free Radic Biol Med 1995; 19: 227-250.

27 O'Neill HC, Rancourt RC, White CW. Lipoic acid suppression of neutrophil respiratory burst: effect of NADPH. Antioxid Redox Signal 2008; 10: 277-285.

28 Suh JH, Shenvi SV, Dixon BM, et al. Decline in transcriptional activity of Nrf 2 causes age-related loss of glutathione synthesis, which is reversible with lipoic acid. Proc Natl Acad Sci USA 2004; 101: 3381-3386.
29 Peterson Shay K, Moreau RF, Smith EJ, Hagen TM. Is $\alpha$-lipoic acid a scavenger of reactive oxygen species in vivo?: evidence for its initiation of stress signaling pathways that promote endogenous antioxidant capacity. IUBMB Life 2008; 60: 362-367.

30 Moini H, Tirosh O, Park YC, Cho KJ, Packer L. R-alpha-lipoic acid action on cell redox status, the insulin receptor, and glucose uptake in 3T3-L1 adipocytes. Arch Biochem Biophys 2002; 397: 384-391.

31 Cho SO, Kim KH, Yoon JH, Kim H. Signaling for integrin alpha5/beta1 expression in Helicobacter pylori-infected gastric epithelial AGS cells. Ann NY Acad Sci 2006; 1090: 298-304.

32 Powelka AM, Sun J, Li J, et al. Stimulation-dependent recycling of integrin beta1 regulated by ARF6 and Rab11. Traffic 2004; 5: 20-36.

33 Caswell PT, Norman JC. Integrin trafficking and th control of cell migration. Traffic 2006; 7: 14-21.

34 Reineke EL, Liu Y, Kao HY. Promyelocytic leukemia protein controls cell migration in response to hydrogen peroxide and insulin-like growth factor-1. $J$ Biol Chem 2010; 285: 9485-9492.

35 Jaumot M, Hancock JF. Protein phosphatases 1 and 2A promote Raf-1 activation by regulating 14-3-3 interactions. Oncogene 2001; 20: 3949-3958. 